\title{
Physico-chemical and technological properties of ceramic tiles: Role of clay minerals on as pressed and dried compacts properties
}

\author{
N. Gouzouli ${ }^{1}$, A. Samdi ${ }^{1}$, R. Moussa ${ }^{1, a}$ and M. Gomina ${ }^{2}$ \\ ${ }^{1}$ LPCMI, FSAC, Université Hassan II - Casablanca, BP. 5366 Maârif, Casablanca, Morocco \\ 2 CRISMAT, UMR 6508 ENSICAENICNRS, 6 Boulevard Maréchal Juin, 14050 Caen Cedex 4, France
}

\begin{abstract}
Chemical, mineralogical and technological properties of an experimental clay are investigated with the aim to substitute for other clays used at present in factories. Flexural strength distributions of green and dry compacts were analysed and correlated to microstructural features with a view to evaluate their drying ability and their mechanical reliability.
\end{abstract}

\section{INTRODUCTION}

Shape-forming of wet powders by unidirectional pressing is one of the more acute steps of the elaboration process of ceramic tiles. Drying the compacts prior to heating may give rise to a great amount of rejects imparted to the formation of flaws which hardly heal upon heating [1]. These flaws originate from moisture gradient between the inner and the periphery of the part, which induces dimensional changes and infers mechanical stresses.

Pastes for ceramic tiles often comprise clay minerals, inert fillers and fluxes, but only the clay minerals strongly react with water. The selection of appropriate clays is then an essential issue. Moreover, in the ceramic industry, for economic and industrial reasons, a minimum number of constituents are needed in the new formulations. They must possess high green properties (plasticity, mechanical properties ...) and also good characteristics upon firing.

This study is aimed at assessing the drying ability of a Moroccan clayey raw material with emphasis on its chemical and mineral composition, and its technological properties. Mechanical behaviour was investigated through the analysis of flexural strength distribution by using an extended Weibull approach [2]. These properties are compared to those of two clays in use at present in factories.

\section{MATERIALS AND METHODS}

\subsection{Materials}

The three clayey materials are a red clay (AR2), a brown clay (AM) and a pink one (ARose). They were mined from the Centre region of Morocco: Berrechid area for AR2 and AM, and Rabat area for ARose. At present, AR2 and $\mathrm{AM}$ are used in local factories, in association with fluxes and fillers in formulations for ceramic tiles. AM is mainly characterized by a good plasticity while AR2 shows a good fusibility. ARose is an experimental batch designed to be substituted in industrial formulations with the aim to enhance properties of green and fired samples [3].

a e-mail: redmoussa@yahoo.fr
Our attention was focussed on the determination of the following parameters:

- Quantitative chemical and mineralogical compositions by means of X-ray fluorescence (FRX, MagiX PRO) and X-ray diffraction analysis on powders (X 'Pert PRO Data Collector, PaNalyticalLci/712), respectively;

- Grain size distribution by using a laser analyser (Horiba LA 920);

- Pfeferkorn plasticity index;

- Density measurement by pycnometry;

- Three point bending strength by using the Flexi 1000 LX set (Gabtec) on wet (different water contents) and dried $\left(110^{\circ} \mathrm{C}\right.$ for 24 hours) specimens with dimensions $20 \times 8 \times 0.6 \mathrm{~cm}^{3}$ obtained by unidirectional pressing at $27 \mathrm{MPa}[4,5]$.

\subsection{Weibull statistical approach}

Brittle solids often exhibit dependence of ultimate mechanical properties on specimen size due to the presence of flaws inherited from elaboration, introduced during manufacturing or in use [6]. Among the numerous models proposed at present for the analysis of the strength of brittle solids $[7,8]$, the Weibull distribution function is the most widely known and applied. This approach describes the specimen under a tensile stress $\sigma$ as a set of $\mathrm{n}$ elements (the links) loaded in series. The specimen break is attributed to the failure of the weakest link (weakest link concept), i.e. the catastrophic extension of a flaw. The three-parameter Weibull distribution is derived assuming the following main assumptions: (i) existence of a single flaw population in the tested volume, (ii) non-interaction between the different flaws, (iii) no contribution of the compressive stresses to fracture and (iv) a time independent strength. The three-parameter Weibull distribution expresses the cumulative probability of failure, $\mathrm{P}$, by:

$$
\mathrm{P}(\sigma)=1-\exp \left[-\mathrm{V}\left(\frac{\sigma-\sigma_{\mathrm{u}}}{\sigma_{0}}\right)^{\mathrm{m}}\right] .
$$

Where $\mathrm{V}$ is the volume under the applied stress $\sigma, \sigma_{\mathrm{u}}$ is a threshold value below which the failure probability is 
zero, $\sigma_{0}$ is a scaling parameter and $\mathrm{m}$ the shape parameter or Weibull modulus which characterizes the width of the strength distribution and gives account of the size effect. For the sake of simplicity $\sigma_{\mathrm{u}}$ is often considered equal to zero. Equation (2) reduces to the two-parameter Weibull distribution:

$$
\mathrm{P}(\sigma)=1-\exp \left[-\left(\frac{\sigma}{\sigma_{0}}\right)^{\mathrm{m}}\right] .
$$

Different estimators are generally used to calculate the probability of failure $\mathrm{Pi}$ for the $\mathrm{i}^{\text {th }}$ strength $\sigma_{i}$ depending on the considered population. The most common ones are [9]:

$$
\begin{array}{r}
P_{i}=\frac{i-0.5}{N}(\text { specimens number less than } 50), \\
P_{i}=\frac{i}{N+1}(\text { specimens number higher than } 50) .
\end{array}
$$

For practical purposes, the shape and scale parameters are assessed by fitting the experimental data through the expression:

$$
\operatorname{Ln}\left[\operatorname{Ln}\left(\frac{1}{1-\mathrm{P}(\sigma)}\right)\right]=m \operatorname{Ln}(\sigma)-\operatorname{mLn}\left(\sigma_{0}\right) .
$$

But when failure is governed by different populations of flaws (assuming that they act independently), a multimodal function is needed. The two-parameter multimodal Weibull distribution function is $[10,11]$ :

$$
\begin{aligned}
\mathrm{P}(\sigma)= & 1-\mathrm{q} \exp \left[-\left(\frac{\sigma}{\sigma_{01}}\right)^{\mathrm{m}_{1}}\right] \\
& -(1-\mathrm{q}-\mathrm{k}) \exp \left[-\left(\frac{\sigma}{\sigma_{02}}\right)\right]^{\mathrm{m}_{2}}-\mathrm{k} \exp \left[-\left(\frac{\sigma}{\sigma_{03}}\right)\right]^{\mathrm{m}_{3}} .
\end{aligned}
$$

Where $\mathrm{m}_{1}, \mathrm{~m}_{2}, \mathrm{~m}_{3}, \sigma_{01}, \sigma_{02}$ and $\sigma_{03}$ are the shape and scale parameters of the three populations of flaws, respectively; $\mathrm{q}$ and $\mathrm{k}$ are the proportions of the most and less severe flaws respectively. In practice, a number $\mathrm{N}$ of identical specimens is loaded to rupture, the calculated strengths are then sorted and the probability of failure is calculated for each strength value (Eq. 5). The different parameters of the distribution function are evaluated by fitting equation (6) to the experimental data.

\section{RESULTS AND DISCUSSION}

\subsection{Chemical and mineralogical compositions}

The chemical compositions of the raw materials are given in Table 1. Silica is the most important constituent for all the clays. AR2 and AM contain non negligible amounts of $\mathrm{Fe}_{2} \mathrm{O}_{3}, \mathrm{CaO}$ and $\mathrm{MgO}$, compared to ARose.

XRD analysis reported in Fig. 1 brings to the fore the presence of free silica in form of quartz. In ARose and AM raw materials, kaolinite and muscovite are both important
Table 1. Chemical composition (wt. \%) of the clays.

\begin{tabular}{|l|c|c|c|}
\hline & AR2 & AM & ARose \\
\hline $\mathrm{SiO}_{2}$ & 56.3 & 52.7 & 64.9 \\
\hline $\mathrm{Al}_{2} \mathrm{O}_{3}$ & 13.6 & 23.1 & 21.4 \\
\hline $\mathrm{CaO}$ & 4.4 & 1.4 & 0.5 \\
\hline $\mathrm{MgO}$ & 4.5 & 2.0 & - \\
\hline $\mathrm{Fe}_{2} \mathrm{O}_{3}$ & 5.5 & 6.4 & 1.5 \\
\hline $\mathrm{Na}_{2} \mathrm{O}$ & 0.2 & 0.6 & 1.1 \\
\hline $\mathrm{K}_{2} \mathrm{O}$ & 4.5 & 2.8 & 3.3 \\
\hline $\mathrm{SO}_{3}$ & 0.2 & 0.2 & - \\
\hline $\mathrm{TiO}_{2}$ & 0.7 & 1.1 & 0.9 \\
\hline $\mathrm{P}_{2} \mathrm{O}_{5}$ & 0.1 & 0.2 & 0.2 \\
\hline $\mathrm{MnO}$ & 0.1 & 0.1 & - \\
\hline Ignition losses at $1000^{\circ} \mathrm{C}$ & 9.9 & 9.5 & 6.2 \\
\hline
\end{tabular}

Table 2. Mineralogical composition (in wt. \%) of AR2, AM, and ARose clays.

\begin{tabular}{|l|c|c|c|c|}
\hline & Quartz & Muscovite & Kaolinite & Dolomite \\
\hline AR2 & 48.2 & 37.3 & - & 14.5 \\
\hline AM & 41.4 & 23.2 & 29.15 & 6.25 \\
\hline Arose & 36.61 & 27.34 & 36.05 & - \\
\hline
\end{tabular}
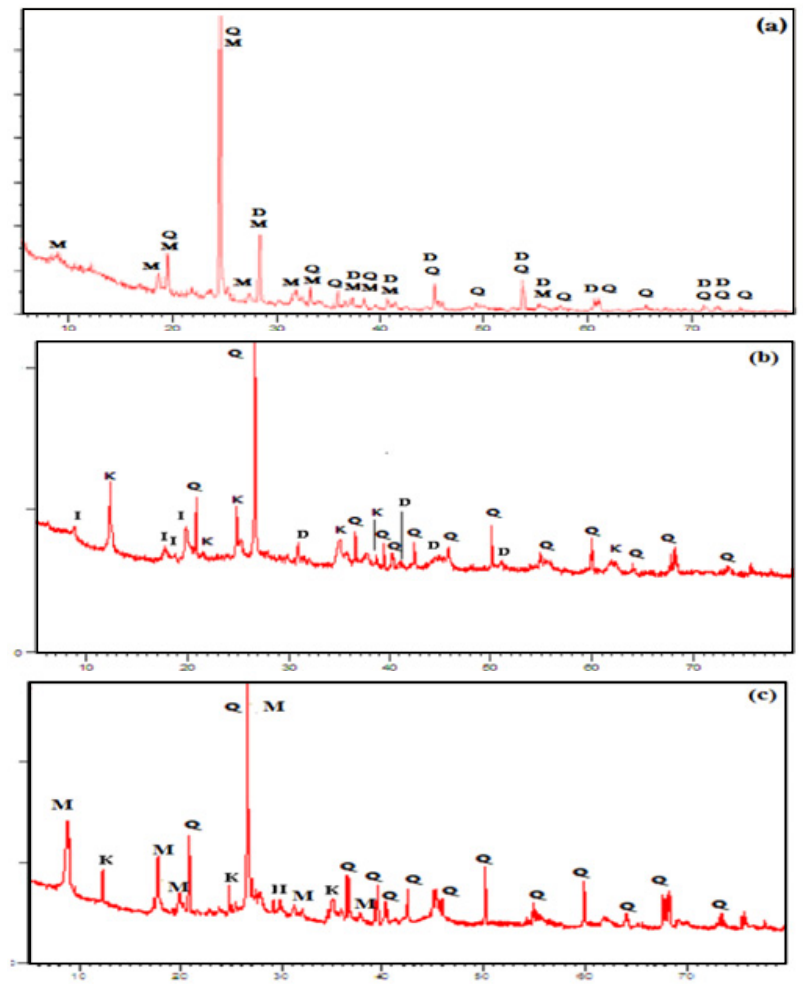

Figure 1. (a, b, c): Powder X-ray diffraction patterns of (a) AR2, (b) AM, and (c) ARose. K: Kaolinite; M: Muscovite; Q: Quartz; D: Dolomite.

clay minerals while in AR2 muscovite is more dominant (Table 2). However, the amount of clay minerals depends on the considered material: an indicator of this amount is the $\mathrm{Al}_{2} \mathrm{O}_{3} / \mathrm{SiO}_{2}$ mass ratio which increases from 0.24 for AR2 to 0.33 for ARose and up to 0.44 for AM. The presence of carbonate (dolomite) was also identified in AR2 and AM. 

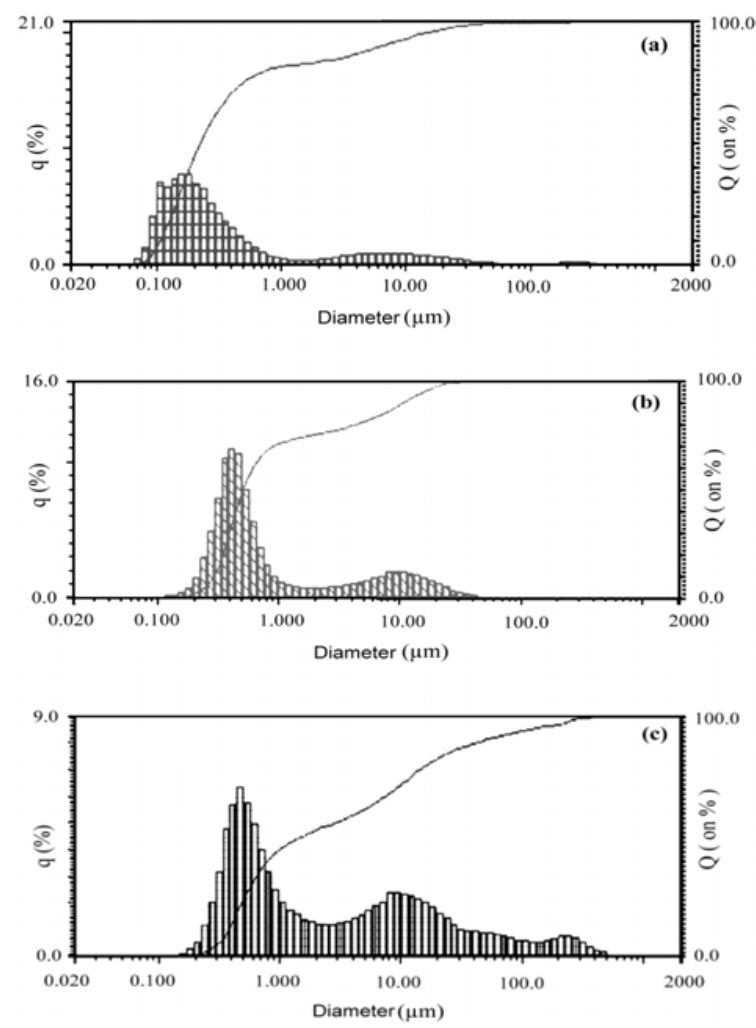

Figure 2. Grain size distribution for (a) AR2, (b) AM and (c) ARose.

\subsection{Grain size distribution}

Figures 2 ( $\mathrm{a}, \mathrm{b}$ and $\mathrm{c}$ ) clearly show the multimodal grain size distributions in AR2, AM and ARose materials, respectively. AR2 comprises very fine grains $(<0.1 \mu \mathrm{m})$ while the multimodal trend is more marked for AM and ARose, with the latter clearly showing a wide grain size distribution of up to $500 \mu \mathrm{m}$.

\subsection{Technological properties}

The technological properties of the three raw materials: plasticity index, green and dry densities, green $(5 \%$ moisture) and dry strengths are reported in Table 3. The inter comparison of these values is tricky as their evolution depend upon a great number of parameters (chemical composition, nature of the clay minerals, grain size distribution...). However, few remarks arise:

(i) The plasticity index decreases from $\mathrm{AM}$ ARose to AR2 and this correlates with the $\mathrm{Al}_{2} \mathrm{O}_{3} / \mathrm{SiO}_{2}$ ratio revealing the high clay minerals content. Nevertheless, paste plasticity depends upon many others factors.

(ii) The green body strength is of major importance in the elaboration process of clay-based ceramics: high green strength enables minimizing the number of rejects prior to firing. On that basis, ARose is not the best clay.
Table 3. Technological parameters of the clays.

\begin{tabular}{|l|c|c|c|}
\hline & AR2 & AM & ARose \\
\hline Plasticity index W $(\%) \mathrm{H}_{0} / \mathrm{H}=3.3$ & 19.5 & 25.1 & 23.8 \\
\hline$\sigma_{\text {green }}(\mathrm{MPa})$ & 0.62 & 0.96 & 0.51 \\
\hline$\sigma_{\text {dry }}(\mathrm{MPa})$ & 1.2 & 3.28 & 1.83 \\
\hline $\mathrm{D}_{\text {ap }}($ green $)\left(\mathrm{g} / \mathrm{cm}^{3}\right)$ & 2.01 & 2.1 & 2.03 \\
\hline $\mathrm{D}_{\text {ap }}($ dry $)\left(\mathrm{g} / \mathrm{cm}^{3}\right)$ & 1.99 & 2.06 & 1.98 \\
\hline
\end{tabular}
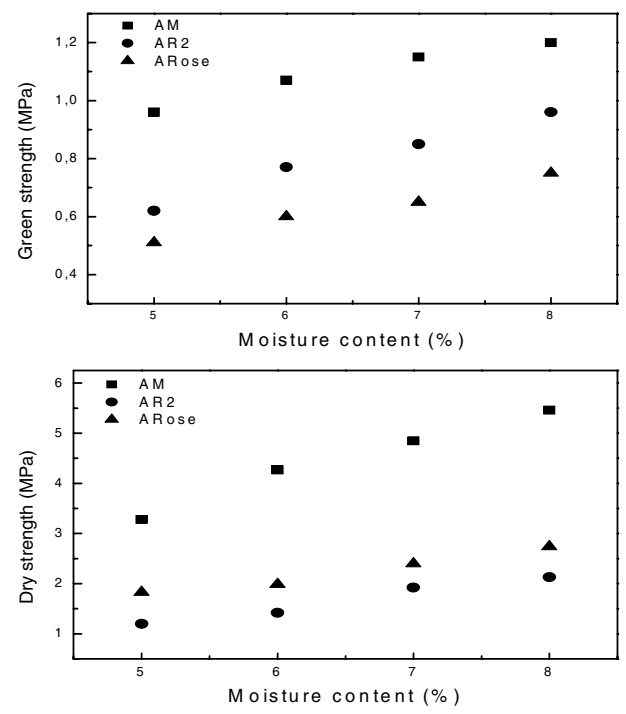

(a)

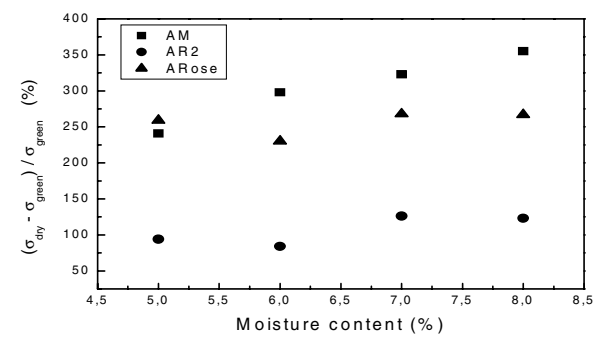

(b)

(c)

Figure 3. Evolution of the (a) green and (b) dry flexural strengths as a function of moisture content.

The influence of moisture content (in the range 5-8 wt.\%) on the green and dry strengths is depicted in Figs 3 (a, b and c):

- The general trend in Fig. 3a for the three raw materials is a rise of the green strength as the moisture content is increased. The observed differences between AM, ARose and AR2 are ascribed to the grain size distribution and the plasticity. Indeed, the appreciable plasticity of AM with finer grain size results in a high strength; at the opposite ARose shows the lowest strength although its plasticity is higher than AR2. This may be explained by the coarser grain size distribution in ARose (50\% of grains with size above $2 \mu \mathrm{m})$.

- Upon drying (Fig. 3b), the same trends as reported above are noted except for AR2 whose strength slightly increases but is now far short of ARose. This may be explained by non-mastered drying conditions relevant to the very fine grain size distribution which promotes microcracking [5].

- The relative benefit of drying $\left(\sigma_{\text {green }} \rightarrow \sigma_{\text {dry }}\right)$ can be evaluated by the $\left(\sigma_{\text {dry }}-\sigma_{\text {green }}\right) / \sigma_{\text {green }}$ ratio. For 

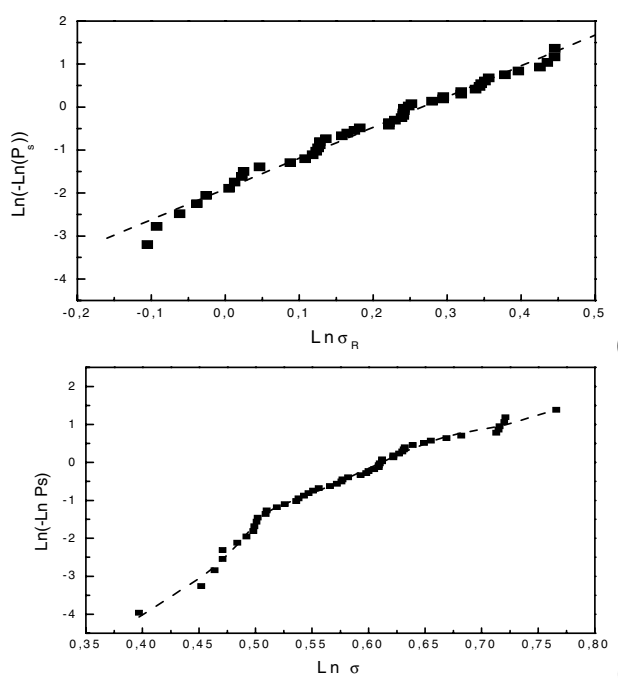

(a)

Figure 4. Experimental Weibull plots and associated fitted curves for (a) AR2 and (b) ARose.

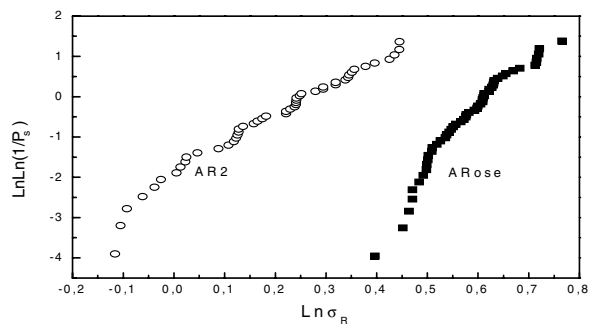

Figure 5. Comparison of the Weibull plots of AR2 (a) and ARose (b).

Table 4. Weibull strength distribution analysis of AR2 and ARose.

\begin{tabular}{|l|c|c|}
\hline & AR2 & Arose \\
\hline $\mathrm{m}_{1}$ & $7.16 \pm 0.13$ & $77.84 \pm 4.6$ (population: $\mathrm{q}=13 \%)$ \\
\hline $\mathrm{Ln} \sigma_{01}$ & $-1.906 \pm 0.03$ & 0.50 \\
\hline $\mathrm{m}_{2}$ & - & $18.01 \pm 0.52$ (population: $\mathrm{k}=16 \%)$ \\
\hline $\mathrm{Ln} \sigma_{02}$ & - & $0.606 \pm 0.01$ \\
\hline $\mathrm{m}_{3}$ & - & $25.63 \pm 3.69($ population $=71 \%)$ \\
\hline $\mathrm{Ln} \sigma_{03}$ & - & $0.74 \pm 0.03$ \\
\hline
\end{tabular}

moisture content of 5\%, drying induces comparable effects on AM and ARose: the benefit is about $250 \%$, which is higher than that for AR2 (94\%).

AR2 and ARose batches with 5 wt.\% moisture were pressed at $27 \mathrm{MPa}$ (applied conditions in factory) and dried in a oven at $110^{\circ} \mathrm{C}$ for 24 hours. The mean values of the flexural strength are $1.21 \pm 0.20 \mathrm{MPa}$ and $1.80 \pm$ $0.15 \mathrm{MPa}$ for AR2 and ARose, respectively. To get a better insight on the mechanical behaviour, the strength distributions were analysed in the frame of the Weibull statistical approach. The experimental values are reported in Fig. 4a for AR2 (Fig. 4b for ARose) in the form of fitted curves calculated from Eq. (6). The fitting parameters are reported in Table 4. It appears that AR2 presents an unimodal behaviour while ARose displays a multimodal one. The general trends are fairly well described by assuming one population of defects for AR2, whereas three populations of defects are inferred for ARose. This can be ascribed to the extended grain size distribution reported above, which may generate a huge size distribution of defects. The direct comparison of the two sets of strength distributions clearly shows higher and less scattered values for ARose (Fig. 5), making it a more reliable material.

\section{CONCLUSION}

Physico-chemical investigations of three clayey raw materials revealed that they possess different mineralogical composition, different structural characteristic and thus different technological properties. These properties essentially impact the behaviour upon drying, specifically the green and dry strengths. The difference in behaviour has then been explained by the association of the effects of two key parameters: good plasticity and narrow grain size distribution, in the case of AM material. Flexural strength distribution analysis by using the Weibull statistical approach suggests that AR2 turns out to present merely unimodal behaviour i.e. a homogeneous population of flaws. However, the strength distribution of ARose is fairly well fitted only when a multimodal distribution (three populations of flaws) is considered, and this is probably relevant to the coarser grain size distribution which may generate flaws with sizes in a huge range. Physico-chemical analyses and mechanical characteristics of sintered materials with ARose clay will soon be published.

\section{References}

[1] J. D. Griffith, R. Brough, R. Harrison, W. Roberts, R. C. P. Cubbon, Clay Based Materials for the Ceramic Industry, edited by H. Nosbusch and I.V. Mitchell, Elsevier Applied Science, 85-91 (1988).

[2] W. Weibull, Proc. Ing. VatenskapAkad. Handl., 151 (1939).

[3] N. Gouzouli, Innov' Act report, Contrat R\&D Maroc-GTZ, Morocco (2008).

[4] H. Zanzoun, Thèse de Doctorat de l'Université Hassan II, Casablanca, Morocco (1995).

[5] A. Sarhiri, Thèse de Doctorat de l'Université Hassan II, Casablanca, Morocco (2003).

[6] A. Marcellan, Thèse de Doctorat, Ecole Nationale Supérieure des Mines, Paris, France (2003).

[7] W. Weibull, J. Appl. Mech., 18 (3), 293-297 (1951).

[8] A. Jayatilaka, K. Trustrum, J. Mater. Sci., 12, 1426 (1977).

[9] M. El Asloum, J. B. Donnet, G. Guilpain, M. Nardin, J. Schutz, J. Mat. Sci., 27 (1): 115-149 (1989).

[10] C. P. Beetz, Fib. Sci. Tech., 16: 45-59 (1982).

[11] P. Zink, J. F. Gérard, H.D. Wagner, Engineering Fracture Mechanics 69, 1049-1055 (2002). 